\title{
Change of initial oral antidiabetic therapy in type 2 diabetic patients
}

\author{
Arian Plat $\cdot$ Fernie Penning-van Beest • \\ Sophia Kessabi $\cdot$ Martijn Groot $\cdot$ Ron Herings
}

Received: 19 December 2008/ Accepted: 6 August 2009/Published online: 20 August 2009

(C) Springer Science+Business Media B.V. 2009

\begin{abstract}
Objective To explore the 'real-life' therapy of type 2 diabetes mellitus with oral antidiabetic drugs (OADs). Methods From the PHARMO Record Linkage System comprising linked drug dispensing and clinical laboratory data from approximately 2.5 million individuals in the Netherlands, among others, new users of OADs were identified in the period 1999-2004. New users, aged 30 years and older, without insulin use before cohort entry date and with at least one year follow-up were included. We determined per initial therapy patient characteristics and first therapy change. Results Overall 35,514 patients were included. Metformin and sulfonylureas (SU) were the most frequent initial therapy. Patients on thiazolidinedione (TZD) monotherapy had lower percentages baseline $\mathrm{HbA1c} \geq 7 \%$ compared to patients on metformin and SU. The proportion of patients still on initial therapy after one year ranged from $46 \%$ (TZDs) to around 60\% (SU). Among patients starting on monotherapy, add-on (15-20\%) and discontinuation (16-25\%) of therapy
\end{abstract}

A. Plat $(\bowtie) \cdot$ F. Penning-van Beest

PHARMO Institute, PO Box 85222, 3508 AE Utrecht,

The Netherlands

e-mail: arian.plat@pharmo.nl

S. Kessabi

Novartis Pharma AG, Basel, Switzerland

M. Groot

Novartis Pharma B.V., Arnhem, The Netherlands

R. Herings

PHARMO Institute, Utrecht, The Netherlands

R. Herings

Department of Health Policy \& Management, Erasmus Medical

Centre, Rotterdam, The Netherlands occurred most frequently. In patients starting on combination therapy, a switch occurred in $30 \%$ of the patients. Conclusion In more than $40 \%$ of the patients a change in initial OAD-therapy is already observed in the first year of therapy. Maintaining patients on initial therapy remains a challenge.

Keywords Diabetes - Netherlands ·

Oral antidiabetic agents · Pharmacoepidemiology ·

Treatment pattern

\section{Impact of findings on practice}

- In the Netherlands, in more than $40 \%$ of the patients with type 2 diabetes mellitus, a change in initial OADtherapy is already observed in the first year of therapy.

- New users of OADs may benefit from frequent monitoring of effectiveness on initial therapy.

\section{Introduction}

The prevalence of type 2 diabetes mellitus (T2DM) is growing tremendously. By 2030, T2DM is estimated to affect more than 350 million people worldwide [1]. Changing lifestyle and dietary measures are usually the first step in therapeutic and preventive management of this disease. The second step is pharmacotherapy with an oral antidiabetic drugs (OADs). In the early 1990s, three groups of OADs were available, that is, biguanides (metformin), sulphonylureas (SUs; e.g. tolbutamide) and $\alpha$-glucosidase inhibitors (e.g. acarbose). In 2000, a new group of OADs became available: the thiazolidinediones (TZDs; e.g. pioglitazone). 
The objective of the pharmacological treatment in T2DM is to control glycaemic parameters in order to minimize the risk of long-term complications [2]. In particular, it is important to manage cardiovascular risk factors, because T2DM accelerates vascular occlusion and much of the excess mortality is due to cardiovascular mortality [2]. Although clinical trials and hospital-based cohort studies have established the merits of different OAD-therapy strategies [2], only studies using 'real life' data include the complete range in diversity with regard to patient characteristics and actual treatment patterns. This also provides an opportunity to view OAD-therapy in the light of the guidelines.

\section{Aim of the study}

The aim of the present study was to explore the 'real life' therapy of T2DM with OADs.

\section{Methods}

\section{Setting}

Data for this retrospective cohort study were obtained from the PHARMO Record Linkage System (PHARMO RLS), which includes, among other databases, the drug dispensing records from community pharmacies linked on a patient level to hospital discharge and clinical laboratory records of approximately 2.5 million individuals in defined areas of the Netherlands. These regions are representative of all of the Netherlands [3]. The computerized drug-dispensing histories contain data concerning the dispensing date, the prescriber, the prescribed dosage regimen, the dispensed quantity and the estimated legend duration of use. All drugs are coded according to the Anatomical Therapeutic Chemical (ATC) Classification. The hospital records include detailed information concerning the primary and secondary discharge diagnoses, procedures, and dates of hospital admission and discharge. All diagnoses are coded according to the International Classification of Diseases, 9th edition (ICD-9-CM).

The clinical laboratory records comprise all requests issued by general practitioners and medical specialists. All tests, processed by auto-analyzers directly linked to the clinical laboratory computer, are routinely validated and recorded independently of the test-results or physician.

\section{Subjects}

The source population included all new users of OAD (ATC-code: A10B) from 1 January 1999 to 31 December
2004. Patients had a registration in the PHARMO RLS for at least one year before the first OAD dispensing (cohort entry date). A patient was defined new user of OAD, if none of these drugs were dispensed for at least one year before cohort entry date. New users, aged 30 years and older, without insulin use before cohort entry date and at least 1 year follow-up, were defined as eligible for inclusion. Patients with T2DM as a complication of other preexisting conditions (e.g. Cushing's syndrome, disease of pancreas, pregnancy) were excluded based on hospital admissions for relevant diagnoses before cohort entry date.

\section{Treatment pattern}

For patients starting on monotherapy with metformin, SU or TZD or on combination therapy with metformin $+\mathrm{SU}$ or metformin $+\mathrm{TZD}$, the treatment pattern in the first year was determined. For each patient, all OAD dispensings in the first year after therapy onset were converted into episodes of continuous use of a specific OAD, based on Catalan's method [4]. The proportion of patients remaining on initial OAD-therapy was defined as the number of days of continuous use of the initial OAD from the cohort entry date onwards (that is the duration of the first episode). For patients not remaining on initial OAD-therapy, defined as $<365$ days of continuous use of the initial OAD, the first change in therapy was determined in the one-year period after start, subdivided into add-on, switch and discontinuation.

\section{Statistical analyses}

All data were analyzed using SAS programs organized within SAS Enterprise Guide version 3.0 (SAS Institute Inc., Cary, NC, USA) and conducted under UNIX using SAS version 9.1.

\section{Results}

\section{Patient characteristics}

The source population included 46,183 new OAD users. Of these, 35,514 fulfilled the inclusion criteria and were included in the study cohort. Table 1 shows their general characteristics.

The most frequently used initial OAD-therapies were metformin $(14,277)$ and SU $(18,876)$. TZD monotherapy was used by 310 patients. Patients starting on TZD monotherapy were more often male $(51 \%)$ and younger and were more frequently treated by an internist $(28 \%)$. Three-quarters of new OAD users whose initial therapy was metformin, SU or metformin $+\mathrm{SU}$, had $\mathrm{HbA} 1 \mathrm{c} \geq 7 \%$ 
Table 1 General characteristics at baseline per type of initial OAD-therapy

\begin{tabular}{|c|c|c|c|c|c|c|c|c|c|c|c|c|}
\hline & \multicolumn{12}{|c|}{ Type of initial OAD-therapy } \\
\hline & \multicolumn{2}{|c|}{$\begin{array}{l}\text { Metformin } \\
(\mathrm{N}=14,277)\end{array}$} & \multicolumn{2}{|c|}{$\begin{array}{l}\text { SU } \\
(\mathrm{N}=18,876)\end{array}$} & \multicolumn{2}{|c|}{$\begin{array}{l}\text { TZD } \\
(\mathrm{N}=310)\end{array}$} & \multicolumn{2}{|c|}{$\begin{array}{l}\text { Metformin }+\mathrm{SU} \\
(\mathrm{N}=1,426)\end{array}$} & \multicolumn{2}{|c|}{$\begin{array}{l}\text { Metformin }+ \text { TZD } \\
(\mathrm{N}=73)\end{array}$} & \multicolumn{2}{|c|}{$\begin{array}{l}\text { Other OAD }{ }^{a} \\
(\mathrm{~N}=552)\end{array}$} \\
\hline & $\mathrm{n}$ & $\%$ & $\mathrm{n}$ & $\%$ & $\mathrm{n}$ & $\%$ & $\mathrm{n}$ & $\%$ & $\mathrm{n}$ & $\%$ & $\mathrm{n}$ & $\%$ \\
\hline \multicolumn{13}{|l|}{ Gender } \\
\hline Male & 6,709 & 47.0 & 9,426 & 49.9 & 157 & 50.6 & 747 & 52.4 & 40 & 54.8 & 260 & 47.1 \\
\hline Female & 7,568 & 53.0 & 9,450 & 50.1 & 153 & 49.4 & 679 & 47.6 & 33 & 45.2 & 292 & 52.9 \\
\hline \multicolumn{13}{|l|}{ Age (years) } \\
\hline $30-44$ & 1,528 & 10.7 & 1,358 & 7.2 & 41 & 13.2 & 144 & 10.1 & 11 & 15.1 & 86 & 15.6 \\
\hline $45-54$ & 3,014 & 21.1 & 2,843 & 15.1 & 57 & 18.4 & 251 & 17.6 & 17 & 23.3 & 104 & 18.8 \\
\hline $55-64$ & 4,100 & 28.7 & 4,448 & 23.6 & 85 & 27.4 & 355 & 24.9 & 21 & 28.8 & 145 & 26.3 \\
\hline $65-75$ & 3,543 & 24.8 & 5,310 & 28.1 & 95 & 30.6 & 382 & 26.8 & 17 & 23.3 & 127 & 23.0 \\
\hline$\geq 76$ & 2,092 & 14.7 & 4,917 & 26.0 & 32 & 10.3 & 294 & 20.6 & 7 & 9.6 & 90 & 16.3 \\
\hline \multicolumn{13}{|l|}{ Initial prescriber } \\
\hline General practitioner & 12,572 & 88.1 & 16,006 & 84.8 & 209 & 67.4 & 1,060 & 74.3 & 54 & 74.0 & 325 & 58.9 \\
\hline Internist & 1,148 & 8.0 & 1,729 & 9.2 & 87 & 28.1 & 210 & 14.7 & 16 & 21.9 & 148 & 26.8 \\
\hline Cardiologist & 105 & 0.7 & 218 & 1.2 & 2 & 0.6 & 38 & 2.7 & 2 & 2.7 & 10 & 1.8 \\
\hline Specialist, other & 452 & 3.2 & 923 & 4.9 & 12 & 3.9 & 118 & 8.3 & 1 & 1.4 & 69 & 12.5 \\
\hline \multicolumn{13}{|l|}{$\mathrm{HbA1c}$ at baseline ${ }^{\mathrm{d}}$} \\
\hline & \multicolumn{2}{|c|}{$\mathrm{n}=1.859$} & \multicolumn{2}{|c|}{$\mathrm{n}=1,963$} & \multicolumn{2}{|c|}{$\mathrm{n}=58$} & \multicolumn{2}{|l|}{$\mathrm{n}=167$} & \multicolumn{2}{|l|}{$\mathrm{b}$} & \multicolumn{2}{|l|}{$\mathrm{c}$} \\
\hline $\mathrm{HbA} 1 \mathrm{c}<7 \%$ & 501 & 26.9 & 429 & $21.9 \%$ & 27 & 46.6 & 40 & $24.0 \%$ & $\mathrm{~b}$ & $\mathrm{~b}$ & $\mathrm{c}$ & $\mathrm{c}$ \\
\hline $\mathrm{HbA} 1 \mathrm{c} \geq 7 \%$ & 1.358 & 73.1 & 1,534 & $78.1 \%$ & 31 & 53.4 & 127 & $76.0 \%$ & $\mathrm{~b}$ & $\mathrm{~b}$ & $\mathrm{c}$ & $\mathrm{c}$ \\
\hline
\end{tabular}

$O A D$ oral antidiabetic drug; $S U$ sulphonylurea; $T Z D$ thiazolidinedionen

a Includes acarbose, glinidines, other combination therapies with OAD, and combination therapy of OADs and insulin

b The number of patients on initial metformin + TZD combination therapy $(n=4)$ was too small, therefore these patients were excluded from this $\mathrm{HbA1c}$-analysis

c For patients who started on other types of OAD, HbA1c-values were not studied

d HbA1c levels were considered to be at baseline if they had been determined within a period up to 2 years prior to the cohort entry date

at start of initial therapy. Patients with HbA1c measurements were representative for the entire cohort.

First treatment change

Table 2 shows the first change in therapy within one year after start per type of initial OAD-therapy.
The proportion of patients still on initial therapy after one year ranged from $46 \%$ (TZDs) to around 60\% (SU). Among those who started on monotherapy, add-on (15$20 \%$ ) and discontinuation (16-25\%) of therapy occurred most frequently. In patients starting on combination therapy, a switch was the most common first change in therapy and occurred in about one-third of the patients.

Table 2 First therapy change within one year after start, per type of initial OAD

\begin{tabular}{|c|c|c|c|c|c|c|c|c|c|}
\hline \multirow[t]{2}{*}{ Initial OAD-therapy } & \multirow{2}{*}{$\begin{array}{l}\text { All patients } \\
\mathrm{n}\end{array}$} & \multicolumn{2}{|c|}{ Patients with a change } & \multicolumn{2}{|c|}{ Add-on } & \multicolumn{2}{|c|}{ Switch } & \multicolumn{2}{|c|}{ Discontinue therapy } \\
\hline & & $\mathrm{n}$ & $\%$ & $\mathrm{n}^{\mathrm{a}}$ & $\%$ & $\mathrm{n}^{\mathrm{a}}$ & $\%$ & $\mathrm{n}^{\mathrm{a}}$ & $\%$ \\
\hline Metformin monotherapy & 14,277 & 5,975 & 41.8 & 2,585 & 18.1 & 1,085 & 7.6 & 2,297 & 16.1 \\
\hline SU-monotherapy & 18,876 & 7,605 & 40.3 & 2,895 & 15.3 & 913 & 4.8 & 3,791 & 20.1 \\
\hline TZD-monotherapy & 310 & 167 & 53.8 & 63 & 20.3 & 25 & 8.1 & 78 & 25.2 \\
\hline Metformin + SU combined & 1,426 & 693 & 48.6 & 58 & 4.1 & 475 & 33.3 & 158 & 11.1 \\
\hline Metformin + TZD combined & 73 & 33 & 45.2 & 4 & 5.5 & 22 & 30.1 & 6 & 8.2 \\
\hline
\end{tabular}

$O A D$ oral antidiabetic drug; $S U$ sulphonylurea; $T Z D$ thiazolidinedione

a Expressed as percentage of total per initial OAD-therapy; numbers do not add up to total patients with a change in each initial therapy group because of 18 patients discontinuation could not be assessed 


\section{Discussion}

This study gives a descriptive overview of therapy with OADs. The strength of this study is that pharmacy dispensing records were linked to individual patients, reflecting 'real life' OAD-therapy. This made it possible to follow individual drugs over time. In general, OAD treatment patterns observed in our study were in line with international and national guidelines [5]. Overall, in about $41 \%$ of patients a change in OAD-therapy was observed in the first year. This is in line with the rates of change reported by others [6]. The proportion of patients on initial therapy observed for metformin (58\%) and SU (60\%) were also in agreement with literature [7]. The proportions of patients on initial therapy were the lowest for the TZDs (46\%) and for combination therapies (53\%). A possible explanation might be that these patients were high-risk patients, who were monitored more often and consequently therapy was modified more often. Among patients starting on monotherapy, observed therapy changes were in line with the guidelines: if monotherapy failed, a combination of metformin $+\mathrm{SU}$ was used. Contrary to what might be expected, we did not observe that patients starting on combination therapy often changed all of these initial OADs. Most of these patients switched to monotherapy of one of the two initial OADs. A possible explanation might be overdosing or necessity to increase one drug but not the other. Another important observation is that the majority of the patients had an $\mathrm{HbA} 1 \mathrm{c}$ larger than $7 \%$ at start. However, $16-25 \%$ of the patients on initial OAD monotherapy discontinued therapy without any switch. This might suggest bad tolerance or poor adherence. Further research might provide possible explanations for these observations.

\section{Limitations}

Obesity at initial diagnosis and treatment of T2DM as well as, further, weight gain due to OADs are major problems in T2DM management. Data on BMI, change of weight or use of anti-obesity drugs were not available for this study. Secondly, the distribution of type of initial OAD-therapy in our study population, differed from current daily practice as guidelines have changed [8]. Post-hoc analyses showed that changing of guidelines was also observed in our study population. Stratified by year of start of OAD-therapy, the percentage of patients starting on SU decreased from $75 \%$ in 1999 to $30 \%$ in 2004, while the percentage of patients starting on metformin increased from $18 \%$ in 1999 to $62 \%$ in 2004. Furthermore, characteristics of patients for different OAD-therapies were similar, except for the TZDs. Furthermore, the number of patients on initial TZD therapy was rather small. This might be explained by channeling [9], that is selective prescribing of new drugs to specific patients. Another important limitation is that for only $10 \%$ of the cohort HbA1c data were available at baseline. In our study period, HbA1c levels were measured once a year. Therefore, we decided to include HbAlc values over the longest possible period of time which was also still realistic, i.e. within a period of up to 2 years to cohort entry date. There were no differences in general characteristics between patients with and without HbA1c data, so patients with HbA1c measurements were representative for the entire cohort.

\section{Conclusion}

In daily practice in many patients a change in initial OADtherapy is observed in the first year of therapy, particularly with initial TZD monotherapy. This suggests that this initial therapy was often unsatisfactory, either according to the patient, the physician, or both. New users of OADs may benefit from regular monitoring of effectiveness of proportions of patients on initial therapy, allowing for patienttailored therapy, in case changes in therapy are indicated.

Acknowledgements The authors wish to thank Sjoukje van der Bij for analyzing the data and Michiel van der Linden for his valuable comments on the manuscript.

Funding This study was financially supported by an unrestricted grant from Novartis Pharma AG, Basel, Switzerland.

Conflict of interest statement The PHARMO Institute performs financially supported studies for several pharmaceutical companies, including Novartis.

\section{References}

1. World Health Organisation [www.who.int]. Geneva: Diabetes Facts Sheets (2008); [cited 2009 February 26]. Available from: http://www.who.int/mediacentre/factsheets/fs312/en/index.html/.

2. Ukpds G. Effect of intensive blood-glucose control with metformin on complications in overweight patients with type 2 diabetes (UKPDS 34). UK Prospective Diabetes Study (UKPDS) Group. Lancet. 1998;352:854-65.

3. Herings RM, Bakker A, Stricker BH, Nap G. Pharmaco-morbidity linkage: a feasibility study comparing morbidity in two pharmacy based exposure cohorts. J Epidemiol Community Health. 1992; 46:136-40.

4. Catalan VS, Lelorier J. Predictors of long-term persistence on statins in a subsidized clinical population. Value Health. 2000; 3:417-26.

5. Burgers JS, Bailey JV, Klazinga NS, Van Der Bij AK, Grol R, Feder G. Inside guidelines: comparative analysis of recommendations and evidence in diabetes guidelines from 13 countries. Diabetes Care. 2002;25:1933-9.

6. Cramer JA, Roy A, Burrell A, Fairchild CJ, Fuldeore MJ, Ollendorf DA, et al. Medication compliance and persistence: terminology and definitions. Value Health. 2008;11:44-7. 
7. Boccuzzi SJ, Wogen J, Fox J, Sung JC, Shah AB, Kim J. Utilization of oral hypoglycemic agents in a drug-insured U.S. population. Diabetes Care. 2001;24:1411-5.

8. Rutten GEHM, De Grauw WJC, Nijpels G, Goudswaard AN, Uitewaal PJM, Van der Does FEE, et al. NHG-standaard diabetes mellitus type 2 (tweede herziening) [NHG Practice Guideline Diabetes Mellitus Type 2 (second revision)]. Huisarts Wet. 2006;49:137-52.

9. Krentz AJ, Bailey CJ. Oral antidiabetic agents: current role in type 2 diabetes mellitus. Drugs. 2005;65:385-411. 